\title{
Testing Turing
}

\author{
Irving Massey ${ }^{1}$
}

Received: 21 May 2021 / Accepted: 16 June 2021

(c) The Author(s), under exclusive licence to Springer-Verlag London Ltd., part of Springer Nature 2021

My basic argument is that a computer cannot distinguish between nonsense and metaphor. This would be my new Turing test.

I arrived at this conclusion by a circuitous route, but my argument cannot be understood fully without an awareness of the circumstances that led to this result. I was trying to understand my reactions to a poem. I had been told that it was a bad poem, hackneyed and colorless, but I loved the poem. Taking the position of the hostile critic, I realized that I was sometimes able to see the poem just as a string of foolish phrases, which read, basically, as nonsense, and alternatively, as the inspired, metaphorical expression of true feeling that I felt it to be. Thinking about the nature of this switch, from the literal to the metaphorical, I also realized that it was the sort of change that could not be prescribed or even described: this, the basic aesthetic gesture, remains beyond the boundary of logical definition. It then dawned on me that it might provide a test for the validity of a Turing test, by any definition: can a computer track a mind as it goes through this transformation? I could not envisage such a possibility. This would be a Turing test based on the discipline of aesthetics rather than on technology. A computer could not make the deliberate switch which I have learned, or trained myself, to carry out; it could not choose to switch from one to the other. It would have encountered an undefeatable "adversarial object."

If we hear a phrase such as "having a green thumb," or "hearing a blood-curdling scream," most people know immediately what it means. This is not true of everyone. Some people take the words literally, and experience such expressions as mere nonsense. We usually dismiss such a "defective" response as a minor aberration, found in a small group of people. But this is no esoteric pathology that we can safely ignore. For one thing, there is no established way

Irving Massey

massey@buffalo.edu

1 Professor Emeritus, Department of English and Comparative Literature, University At Buffalo, Buffalo, NY, USA to distinguish between metaphor and nonsense in linguistics or philosophy. What is even more perplexing is the observation that, in people who cannot make the distinction, the brain responds to the two situations in exactly the same way. The failure to distinguish is not a failure of intelligence; it is an actual physiological occurrence.

In an attempt to place myself in the position of someone with Asperger's Syndrome (as it was once called), I learned, with great difficulty, to alternate between experiencing metaphor as such, or as nonsense. (I am glad to say that I found a friend who was also able to execute this manoeuvre.) This practice illuminated for me, with startling clarity, the unique status of the metaphoric experience. There are no instructions that can tell one how to capture a metaphor: either you "get" it or you don't. But the observation of a single brain as it switches between one kind of experience and the other should give one an unusually sharply defined picture of the difference.

Could this kind of investigation, though, risk undermining the autonomy of the aesthetic, so that creativity becomes a manageable commodity like any other? A first step in this direction might be simply to claim that a computer can identify a metaphor among other locutions. If I train a computer to identify metaphors by exposing it to millions of metaphors, it may succeed in doing so, but, as I have pointed out, it would still not be able, at will, to choose to consign a particular metaphor to the category of nonsense.

Nevertheless, the vulnerability to reductionism to which such methods might expose the aesthetic cannot be ignored. The AI enterprise has shown an uncommon interest in metaphor, eager "to move abductively from the outward signs to the underlying situations" (John Barnden); but how to extract value from the "extraneous" elements that are integral to metaphor? Tim Veale, on the other hand, claims that ordinary things can easily be turned into art by some simple procedure, whereas the truth is that making the ordinary into the extraordinary requires the very greatest creative effort. Veale offers to provide a thesaurus of constructed metaphors; but who would want it? It is easy enough to point out the components of a metaphor, as in Othello's "flaming 
minister," but who but a card-carrying idiot would believe that he/she had thereby reduced it to common sense? What such mechanists do not realize is that metaphor is not primarily an embellishment, but an essential instrument of thought. The true purpose of their approach is to destroy creativity by defining that which would cease to exist in its moment of definition.

It may even be argued that the ability to experience metaphor is the very definition of the human.

Curmudgeon Corner Curmudgeon Corner is a short opinionated column on trends in technology, arts, science and society, commenting on issues of concern to the research community and wider society. Whilst the drive for super-human intelligence promotes potential benefits to wider society, it also raises deep concerns of existential risk, thereby highlighting the need for an ongoing conversation between technology and society. At the core of Curmudgeon concern is the question: What is it to be human in the age of the AI machine? -Editor.

Publisher's Note Springer Nature remains neutral with regard to jurisdictional claims in published maps and institutional affiliations. 